\title{
Creating Good Social Behavior through User-friendly Street Environment
}

\author{
Norhafizah Abdul Rahman, Izham Ghani, \\ Azrul Bahaluddin, Nur Huzeima Hussain
}

Faculty of Architecture, Planning \& Surveying,

Universiti Teknologi MARA Perak, 32610 Bandar Seri Iskandar, Perak, Malaysia

norha776@perak.uitm.edu.my

\begin{abstract}
This paper explores the notion of user-friendly streets. The primary concern is to identify the people's need for social behaviours on street environment. The urban street environment is examined in respect of the physical qualities through the analysis of questionnaire surveys. Structured observations of the users' activities and physical environment of the street was conducted as part of the multi-method approach. The users' needs of a user- friendly street in the Malaysian context are mainly similar to the previous theories developed by other countries, especially the developed ones. However, the attributes that contribute to the factors vary for each context.
\end{abstract}

Keywords: Urban streets; social behaviour; people's need; user-friendly

eISSN 2398-4279 @ 2018. The Authors. Published for AMER ABRA cE-Bs by e-International Publishing House, Ltd., UK. This is an open access article under the CC BY-NC-ND license (http://creativecommons.org/licenses/bync-nd/4.0/). Peer-review under responsibility of AMER (Association of Malaysian Environment-Behaviour Researchers), ABRA (Association of Behavioural Researchers on Asians) and cE-Bs (Centre for EnvironmentBehaviour Studies), Faculty of Architecture, Planning \& Surveying, Universiti Teknologi MARA, Malaysia.

DOI: https://doi.org/10.21834/ajqol.v3i12.141 


\subsection{Introduction}

In Malaysian cities, it is hard to find examples of street environments that are friendly and accommodating to pedestrian especially in the advent of motorised transportation. Urban street designs in Malaysia have given priority to the needs of motor vehicles. This has resulted in street environments that are unfriendly to the people on foot that influence the erosion of the street as a public space, which also has an effect on public life and urban users. This research explores the notion of user-friendly streets environment. The primary concern is to identify the people's need for good social behaviours on streets. The street will affect the people uses and activities that shaping the quality and character of urban living.

\subsection{Literature Review}

Streets are an important component of the urban form and the most public of the urban spaces in the city (Abdul Rahman et al., 2016, 2014). Creating streets environment that encourages good social behaviours in our cities is one of the significant goals in city design to create cities for people (Mehta, 2013). The actual needs and preferences in the street should be given more attention to re-evaluate the quality and design of the space over time (Jansson, 2010). The needs of the users in the street depend on their activities in the street. Pedestrian activity or street life can be viewed as travel mode; pedestrian is defined as "one traveling on foot" (Owens, 1993). Street activities are more visible and prominent than activities that occur inside the building and concentration of the activities on the street and their visibility from the street are important in for the place to be noticeable and more attractive (Shamsuddin, 2011).

Outdoor activities in public space can be divided into three categories: necessary activities (going to school or work, waiting for a bus or a person, shopping, etc.), optional activities such as taking a walk, standing around enjoying life, or sitting) and social activities such as children at play, greeting and conversation, seeing and hearing other people (Gehl, 1987; Turel et al., 2007). Gehl (2010) argued that the categories of outdoor spaces are influenced by the quality and the character of the outdoor space. The activities and functions will be developed when the qualities of the space are improved (Gehl, 2010).

User-friendly relates to the theory of inclusive environments of a street where accessibility, safety and usability are the frameworks for inclusive design (Yaakub et al., 2009). Users of the street are anyone who is interested in their local environment and streets (Burton et al., 2006). A review of the related literature suggests that there are three major criteria that contribute to a friendly street: physical qualities, activities or functional qualities, and social qualities. A mixture of activities and use can create a successful community and public space that enables the street to attract more people to come (Shamsuddin, 2011).

\subsection{Methodology}

This study adopts a case study method that is approached in both qualitative and quantitative manner. The street environment is examined in respect of the physical qualities through the 
analysis of questionnaire surveys of 346 respondents selected using quota sampling. The respondents were broadly divided into daily users (those who are constantly engaged with the street) and occasional users (those who are not dependent on the study area. The daily users (shop owners, shopkeepers, vendors, office workers) were selected based on the systematic sampling method using the interval of unit spaces on the ground level of the street (shopping space, restaurants, stalls, stores and shop premises). In this sampling the total of the units within the street of Jalan Tunku Abdul Rahman (JTAR) is divided by the total number of sample size required. Based on observation on site the number of unit spaces is 346, which is divided by 170 (the total number of sample size required). Therefore, the selection of respondents is based on an interval of 2 units.

In this study, structured observations of the users' activities and physical environment of the street was conducted as part of the multi-method approach to record the physical characteristics and the qualities in urban pedestrian environments and to study human activities on the streets. Field observations and documentation of the quality of the site in the form of maps and photographic records were conducted for each sub-area of the case study. Field notes and related photographs were taken of all major elements in the space; buildings use, and landscape use with the physical settings. The data were processed using both qualitative and quantitative approaches and tabulated to find potential patterns and connections. The results from the physical observation and activities observations were used to support the results revealed from the questionnaire surveys. Triangulations were made within and between other data from observation of physical characteristics and activities on the street, interviews and previous research in the literature review.

JTAR is identified as one of the main traditional streets in the city centre due to its inherent socio-cultural role and historical significance as being among the earliest high-streets in the city centre of Kuala Lumpur (Shamsuddin et al., 2010). This street receives the highest concentration of shoppers, visitors and pedestrians and is located in the area which has been dedicated to urban revitalization initiative $(\mathrm{KLCH}, 2003)$.

\subsection{Results and Discussion}

The factors that make a street friendly related to how they use the street, what make them use or not use the street, and what would encourage people to use the street more? To evaluate a user-friendly street, it is important to examine the actual uses and activities and their preferences towards the street.

\subsection{Users activities on street}

Surveys indicate that the functional factors were the main factors that influence the use of the street. Users' activities on the street were very much dependent on their reasons for using the street and also concerning the quality of the environment. The differences concerning how they used the street were affected by the types of activity and the reasons they used the street. The feedback on this is to determine the factors that make them use the street and at the same to justify different factors to cater for different activities. Based on the questionnaire 
survey (Table 1), the most frequent reason they use JTAR is for shopping (30.1\%).

Table 1. The most frequent reasons for street usage by users in JTAR

\begin{tabular}{lll}
\hline Reasons & Frequency ( $\mathrm{N}=161)$ & Percentage $(\%)$ \\
\hline Shopping & 48 & 30.1 \\
Working & 12 & 7.5 \\
Visiting & 18 & 11.4 \\
Meeting friends & 32 & 20.0 \\
Relaxing & 10 & 6.5 \\
Studying & 9 & 5.3 \\
Entertaining & 14 & 8.6 \\
Live there & 17 & 10.3 \\
Others & 1 & 0.3 \\
\hline
\end{tabular}

(Source: Author, 2016)

The results from the observations survey on the activities in JTAR found that nodes of activities were more focused around shopping areas. Shopping activities were more during weekends and the intensity of people was very high around the UO Superstore area and the SOGO area was spreading to Pertama Complex (Fig. 1). Responses from the interviews indicate that a variety of choices, diversity of products and distinctive products that they can get from this street make them love to shop here. Based on the observation, people met friends together enjoying food in restaurants or shopping together. The presence of outdoor cafes and restaurants that provide wireless Internet and air conditioning make the place suitable as a meeting place for people.
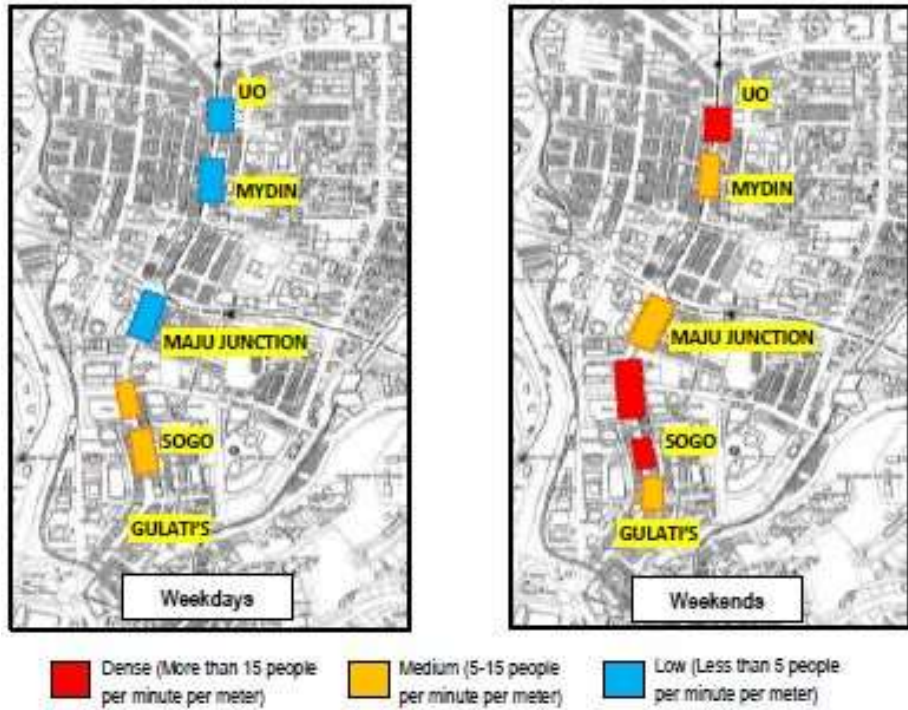

Fig. 1: Nodes of activities during weekdays and weekends

(Source: Author, 2016) 
The feedback from the occasional users shows that 55.6 per cent like to come to JTAR during their free time. Most of them come here during their free time for leisure (33\%), using the facilities (27\%) and shopping (25\%). It was observed that the people used the places for sitting, meeting and walking. However, in the case of JTAR it was found that most of the social activity appeal was passive contacts like seeing and hearing as Gehl (2010) said as 'superficial.'

The results of the survey concerning the degree of visually pleasing places in JTAR show that there was a slight difference in users' perception between two types of the user towards the street's "pleasing environmental quality." An increase in environmental quality will give a boost to optional activities and at the same time will increase the social activities (Gehl, 2010). Most of the activities in JTAR were among the necessary activities such as shopping, working, living there and studying. The awareness concerning a 'friendly street' from the users under necessary activities was lower compared to the group that came to the street for optional and social activities. The daily users were more concerned with the environmental condition compared to the occasional users. The understanding of the activities that occur in the street is important to generate new ideas and also for proposing a new development that is friendly to their users.

\subsection{Supporting factors that make people use the street}

Interesting public spaces, public facilities, greenery and trees and good maintenance are supporting factors to create user-friendly street. This is also identified by Abdul Rahman et al (2017) in her physical observation that JTAR lacks with greenery, landscape elements, pedestrian facilities and poor surface and maintenance of pedestrian walkway.

\subsubsection{Public space}

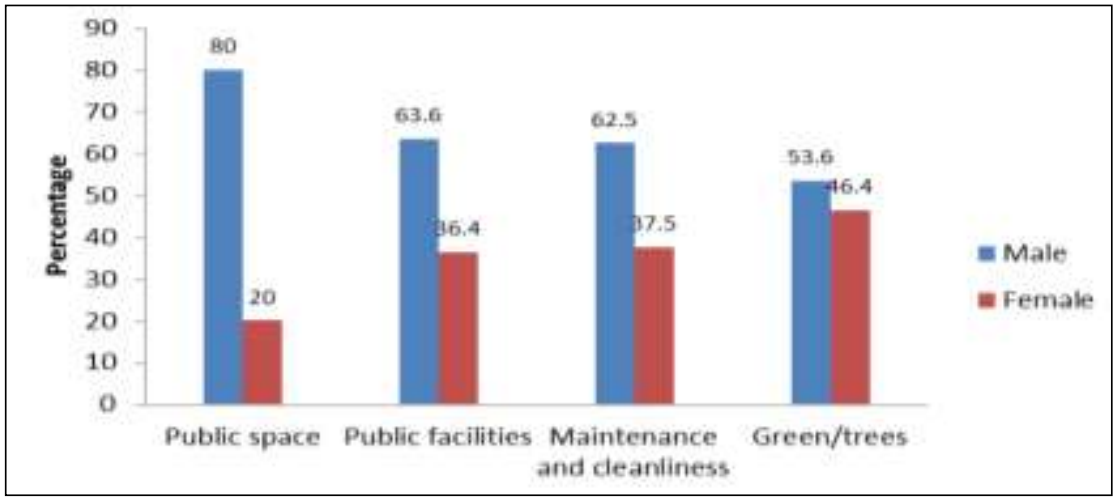

Fig. 2: Factors that make the users use the street by gender (Source: Author, 2016)

The results from the survey indicate that the respondents need interesting public spaces. 
The results of the survey show that the daily group of users mentioned the need for improvement of the public spaces along JTAR the most. This is because this group comprises the users that spend more time in JTAR, and, therefore, need a space that interests them for leisure purposes. The male groups of users indicated the need for improvement of the public spaces along JTAR more compared to the female group of users (Fig. 2). These according to the observation due to the majority of users who spend more time and involved more in outdoor activities are male. This finding concurs with LoukaitouSideris (1995) who found that female are the minority group that uses urban space.

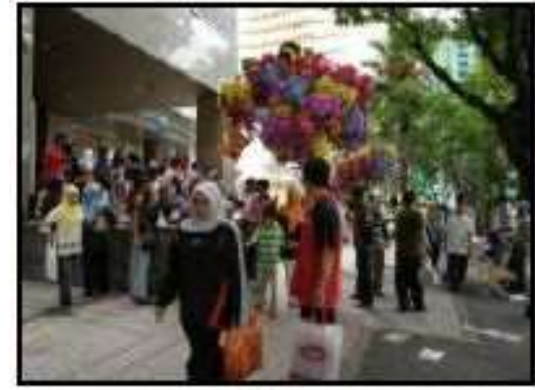

(a)

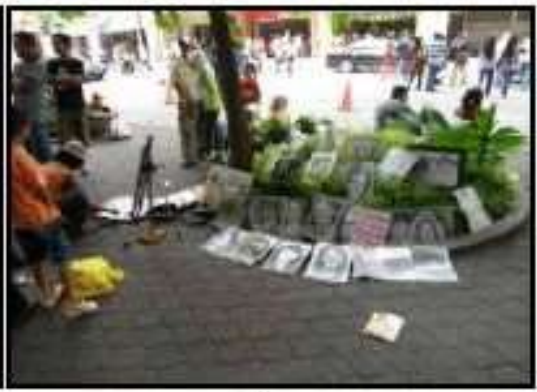

(b)

Fig. 3. (a) and (b) Open space in front of SOGO shopping complex (Source: Author,2016)

The presence of people and activities in space can attract other people to use the space. This was proven by the observation of the SOGO area. The small square in front of the SOGO shopping complex contributes a vibrant public space with musicians, salesman, hawkers selling food and drinks and individuals handing out brochures and flyers (Fig. 3).

\subsubsection{Greenery}

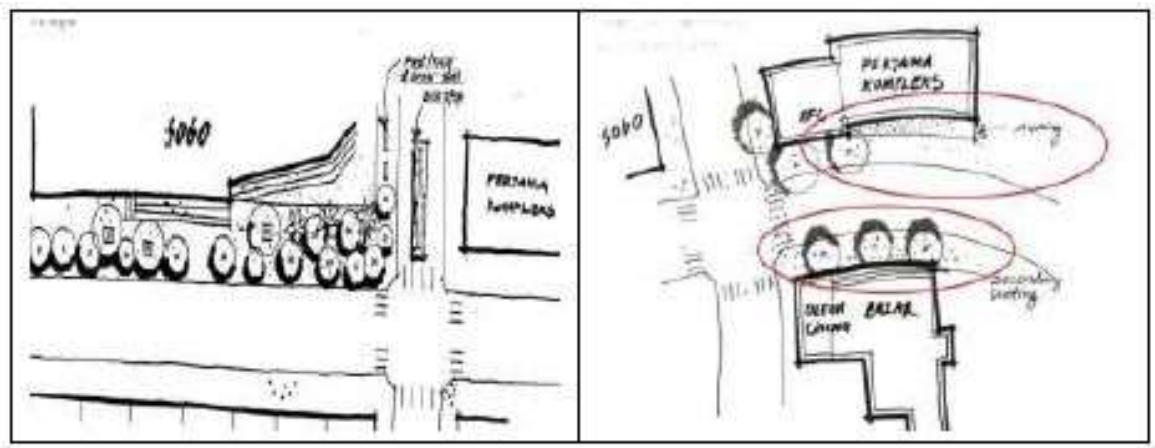

Fig 4. : People use shade from the awnings and trees to get shelter from the sun (Source: Author, 2016) 
It was found in the survey of JTAR that, trees and greenery along the street do affect the uses of the street. In the case of JTAR, there is strong exposure to the sun every day. Therefore tree planting is one of the provisions for providing shade, reducing glare and cooling the atmosphere. The presence of trees/ greenery was felt to have a positive effect on the environment, such as modifying the impact of the microclimate, providing shade from the sun and also acting as a divider between the pedestrian walkway and traffic flow. This is supported by the observations in JTAR where only certain zones have been planted with trees. It was observed that in the areas that have shade trees planted, more activities exist (Fig. 4). The seating located under shady trees also show more use by the street users compared to the seating located in the bare area along the street (Fig. 5).

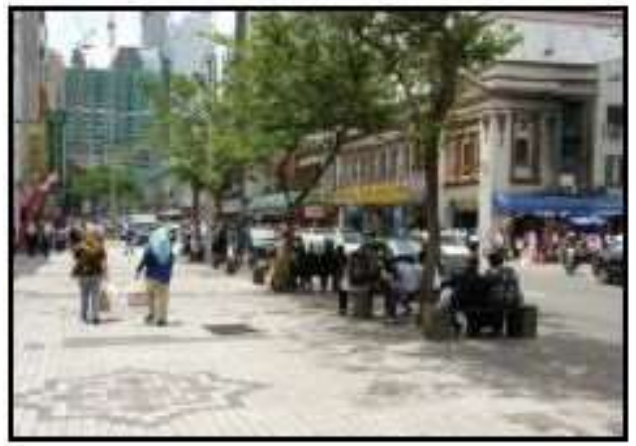

Fig. 5: The static activities happening in the area that provides shade (Source: Author, 2016)

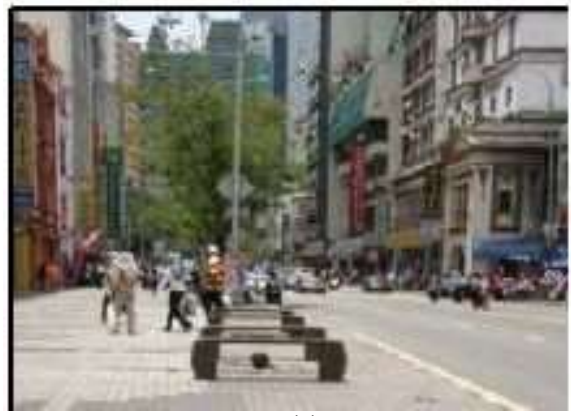

(a)

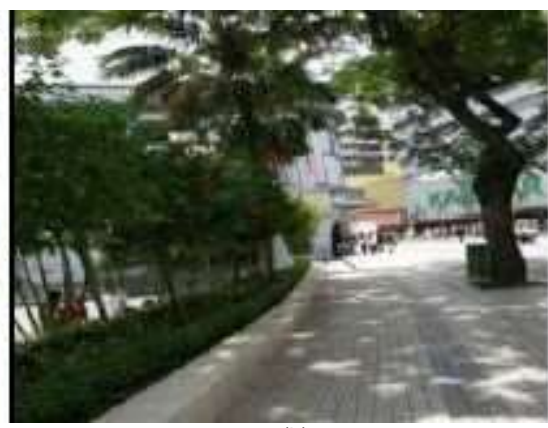

(b)

Fig 6. (a) and (b) Different size and density of tree canopy provide different level of shade (Source: Author, 2016)

However, in some locations, the trees provided are unsuitable for shade because they are not big enough or lack of dense canopy (Fig. 6). Based on observation in JTAR, although there are trees provided along JTAR, only some places are shaded because in most parts the trees are not big and the canopies of the trees are not dense enough to provide shade 
for the pedestrians. The important of green areas was supported in Achariam (2011) research which found that the feedback from respondents that need to be resolved and need attention is having more green areas in the city centre.

In the Malaysian context, the protection from sunlight is a crucial element that can make people feel comfortable and pleasant when using the street. The results of the survey concerning the improvements needed in JTAR reveal that providing covered walkway, trees and greenery which relate to protection from the sun and rain and also cooling aspect are required. This is in line with the statement by Lynch (1981) that streets that are shady provide a setting for activities and can bring people together.

\subsubsection{Public Facilities}

Public facilities are revealed as one of the attributes that contribute to a user-friendly street. Facilities on the street such as dustbins, telephones and toilets are among the attributes perceived by respondents as being the most important to create a convenient. JTAR has some street furniture and pedestrian facilities provided for the pedestrians as well as a police booth. Based on the observation, signage and cues are also provided along JTAR. However, all these elements should be more in number and more legible to the pedestrians that walk along the street.The presence of all these public facilities gives the feeling of convenience to the street users in JTAR. Based on observation in some areas along the street, to the location of such facilities is not appropriate causing a blockage and creating clutter for pedestrian movement. Hence, some of the facilities provided along the street are not sufficient, not function and not well maintain that gives inconvenience to the street users.

\subsubsection{Maintenance and cleanliness}

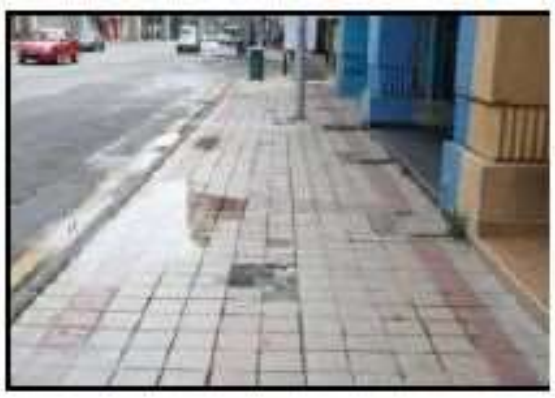

(a)

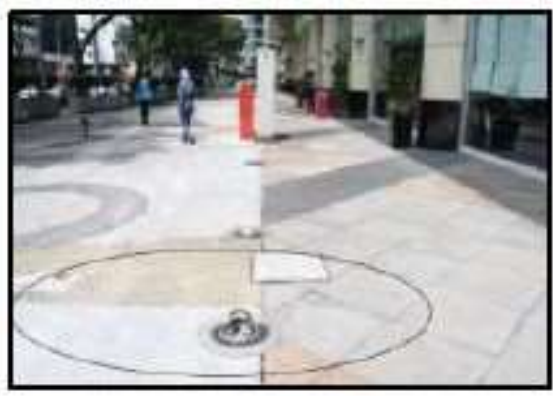

(b)

Fig.7 (a) and (b): Lack of maintenance of pedestrian walkway in JTAR

(Source: Author, 2016)

Good maintenance and cleanliness of the street were another factors that users need most on the street. This is supported by the results of the survey concerning the suggestions for improvements needed to JTAR as this factor became one of the significant factors needed to improve JTAR. It was proven that there were some areas along JTAR that were not well 
maintained and were poor regarding cleanliness (Fig. 7). This not only gives a bad impression and bad views to the street users but also creates the feeling of a lack of safety and discomfort to the street users. This is supported by the feedback from the users' perceptions of streets in the UK who found that the streets most chosen by users are streets that are clean and well maintained (Carmona et al., 2003).

\subsection{Conclusion}

In this paper, the factors that make a street friendly related to how they use the street, what make them use or not use the street, and what would encourage people to use the street more? A user-friendly street will facilitate the creation of a walkable environment that is seen as the more sustainable approach towards city planning and design in the future. There is a danger that the city will end up having streets which are not friendly to the various user groups if we do not understand the design criteria that fit with users' needs and preferences.

The findings revealed that the user needs of a user- friendly street in the Malaysian context are mainly similar to those developed by other countries, especially the developed ones. However, the attributes that contribute to the factors vary for each context, especially between developing and developed countries with different climate and economic level. This paper identifies the factors that need to be considered in future guidelines and policies for the planning and design of urban spaces, in particular for streets in the city centre to create a user-friendly street environment. It is hoped that these factors will be taken into consideration by those involved in the decision- making process concerning urban planning and design.

\section{Acknowledgement}

The authors are grateful to the Ministry of Higher Education (Malaysia) and Universiti Teknologi MARA for sponsoring this research.

\section{References}

Abdul Rahman, N., Ghani, I., Bahaluddin, A., \& Hussain, N. H. (2016). The need for good social behavior through people friendly urban streets. Environment-Behaviour Proceedings Journal, 2(5), 469-477.

Abdul Rahman, N., Md Sakip, S. R., \& Mat Nayan, N. (2016). Physical qualities and activities for a user-friendly shopping street in the context of a Malaysian city. Procedia - Social and Behavioral Sciences, 222, 196-202.

Abdul Rahman, N., Shamsuddin, S., \& Ghani, I. (2014). What makes people use the street?: Towards a liveable urban environment in Kuala Lumpur City Centre. Procedia - Social and Behavioral Sciences, 170, 624-632.

Abdul Rahman, N., \& Md Sakip, S. R. (2014). Relationship between accessibility and safety criteria with the uses of the street: A case study of urban commercial street in Kuala Lumpur city centre. [Online]. Retrieved from https://www.academia.edu/15827062/Relationship between accessibility and safety criteria with the uses of $t$ he_street_A_case_study_of_urban_commercial_street_in_Kuala_Lumpur_city_centre [2016, 12 October]. 
Abdul Rahman, N., et.al. / Asian Journal of Quality of Life (AjQoL), 3(12) Jul / Aug 2018 (p.51-60)

Achariam, N. (2011). KL City Plan 2020 to be gazetted in July. New Straits Times [Online]. Available: www.nst.com

Carmona, M., Heath, T., Oc, T. \& Tiesdell, S. (2003). Public places, urban spaces: The dimensions of urban design. London: Architectural Press.

Gehl, J. (2010). Cities for people. Washington: Island Press.

Gehl, J. (1987). Life between buildings: Using public space. New York: Van Nostrand Reinhold.

KLCH (2003). Kuala Lumpur Structure Plan 2020. Kuala Lumpur: Kuala Lumpur City Hall.

Loukaitou-Sideris, A. (1995). Urban form and social context: Cultural differentiation in the uses of urban parks. Journal of Planning Education and Research, 14, 89-102.

Lynch, K. (1981). A Theory of Good city form. Cambridge, MA: MIT Press.

Yaakub, N.M. \& Hashim, N.R., (2009). Accessibility for disabled and elderly people in Malaysia: Problems and solutions, The Malaysian Surveyor ,Vol.44, No.2 .pp 30-34. 